Aldona Kubica ${ }^{1}$, Marcin Gruchała ${ }^{2}$, Miłosz Jaguszewski², Piotr Jankowski ${ }^{3}$, Damian Świeczkowski², Piotr Merks ${ }^{1}$, Izabella Uchmanowicz ${ }^{4}$

${ }^{1}$ Nicolaus Copernicus University, Collegium Medicum, Bydgoszcz, Poland

2 First Department of Cardiology, Medical University of Gdansk, Poland

${ }^{3}$ Jagiellonian University, Collegium Medicum, Kraków, Poland

${ }^{4}$ Wroclaw Medical University, Wrocław, Poland

\title{
Adherence to treatment - a pivotal issue in long-term treatment of patients with cardiovascular diseases. An expert standpoint
}

\author{
Corresponding author: \\ Aldona Kubica, MD, PhD \\ Department of Health Promotion, \\ Collegium Medicum, Nicolaus \\ Copernicus University \\ ul. Łukasiewicza 1 \\ 85-821 Bydgoszcz, Poland \\ e-mail: aldona.kubica@gmail.com
}

Medical Research Journal 2017;

Volume 2, Number 4, 123-127

10.5603/MRJ.2017.0016

Copyright (C) 2017 Via Medica

ISSN 2451-2591

\begin{abstract}
The adherence to treatment is defined as the extent to which a person's behaviour, including taking medication, following a diet, and/or executing lifestyle changes, corresponds with agreed recommendations from a healthcare provider. Non-adherence to medication may lead to increased morbidity, mortality, and costs to the healthcare system. Therefore, it is pivotal to know the patient's true adherence to medication, understand the causes of low adherence, and take actions to improve adherence.

The authors assumed that individual, complex health education started during hospitalisation and continued after discharge, explaining the pathophysiology and symptoms of the disease, elucidating goals and potential benefits of treatment, and highlighting the risk of premature termination of therapy, with use of additional methods helping patients to remember treatment schedule will enhance adherence to treatment. There is an urgent need to develop and test a dedicated procedure covering all these activities.

Introduction. A substantial proportion of patients with cardiovascular diseases do not respond to the treatment sufficiently [1-3]. Several factors of poor response to medication should be taken into account, including inadequate drug intake [4-6]. To systematise the phenomenon of following medical recommendations, the term "adherence" was proposed. The World Health Organisation (WHO) defines "adherence" as "the extent to which a person's behaviour, including taking medication, following a diet, and/or executing lifestyle changes, corresponds with agreed recommendations from a healthcare provider" [7]. Adherence has been also defined as the "active, voluntary, and collaborative involvement of the patient in a mutually acceptable course of behaviour to produce a therapeutic result" [8]. Previously the term 'compliance' was widely used, particularly in negative concord as 'non-compliance'. Nowadays 'compliance' is associated with a more pejorative connotation than 'adherence' because 'non-compliance issues' are mostly patient-oriented without a deeper view into the different set of factors, e.g. obstacles identified in the healthcare system. Thus, currently in scientific deliberations we usually prefer usage of the term 'adherence' [9].

Keywords: Adherence, cardiovascular diseases, self-reported questionnaires
\end{abstract}

Med Res J 2017; 2 (4): 123-127

\section{The prevalence and consequences of non-adherence}

According to the Food and Drug Administration data, from 30 to $50 \%$ of patients do not exactly adhere to recommendations received from their healthcare providers, which significantly increases the risk of death.
These data were confirmed in several studies [6,10-16]. Non-adherence to medication may lead to increased morbidity, mortality, and costs to the healthcare system $[8,16-19]$. Therefore, it is pivotal to know the true patient's adherence to medication, understand the causes of low adherence, and take actions to improve adherence [20]. 
Results of the Prospective Registry Evaluating Myocardial Infarction: Event and Recovery (PREMIER) trial showed that failure of treatment plan implementation is associated with poor clinical outcome [21]. In 1521 myocardial infarction survivors at one month after discharge from the hospital with the recommendation of combination therapy with three drugs (aspirin, a beta-blocker, and a statin), $12 \%$ of patients discontinued treatment with all three drugs, $4 \%$ - with two drugs, and $18 \%$ - with one drug. One-year survival rate of patients who completely stopped their medication was significantly lower compared with those who continued their therapy (88.5\% vs. $97.7 \%)$. Discontinuation of treatment was an independent risk factor for death (hazard ratio 3.81). Multivariate analysis showed that the probability of discontinuation of all three drugs was higher among those with higher education (hazard ratio 1.76). The impact of older age on treatment discontinuation was higher among women (hazard ratio 1.77) than among men (hazard ratio 1.23) [21]. The Prospective Urban Rural Epidemiology (PURE) study showed that adherence to secondary prevention therapy was more influenced by general socioeconomic factors at the national level than to individual factors, such as age, gender, education level, smoking, body mass index (BMI), hypertension, and diabetes [22]. It is worth mentioning, however, that studies based solely on a quantitative approach may underestimate the true nature of the non-adherence phenomenon, and qualitative studies are highly anticipated to detect nuances that can deteriorate adherence [9].

\section{Determinants of non-adherence}

In several studies the age of patients was indicated as one of the factors affecting adherence to medication [8,14,18-19,23-24]. Comorbidity burden increasing with age is associated with the necessity of polypharmacy. Elderly patients often do not understand the reasons for the complexity of the treatment, and have problems with remembering and adapting to the treatment schedule [25]. Holt et al. conducted a qualitative study based on a focus group, which revealed that memory-related problems and forgetfulness were factors mostly reported by the elderly in the context of the non-adherence phenomenon. Patients emphasised that knowledge about the nature and seriousness of the primary disease, i.e. hypertension, can improve adherence to recommended therapy. These findings may suggest the potential target of new interventions [26]. The Pennsylvania Pharmaceutical Assistance Contract for the Elderly (PACE) study showed that in elderly patients with hypertension, adherence to the treatment plan was worse in the coexistence of asthma or chronic obstructive pulmonary disease (odds ratio
$[O R]=0.43)$, depression $(O R=0.5)$, gastrointestinal disorders (OR $=0.59$ ), or musculoskeletal diseases $(\mathrm{OR}=0.63)$ compared with hypertensive patients without concomitant diseases (OR = 1.0) [27]. Moreover, it was revealed that polypharmacy has a negative impact on the implementation of the treatment plan [18]. In another study, the co-existence of diabetes was found to be an independent factor reducing adherence to treatment [14]. Low adherence occurs in all age groups; however, older patients are particularly exposed to multiple challenges regarding this issue, including difficulty hearing, comprehending, and remembering instructions, managing multiple medications, and tolerating side effects of medication and drug-drug interactions [28]. Due to differences of cultural, social, and medical nature, the adherence determinants for distinct patient populations differ [24]. Many studies have tried to identify patients jeopardised with future failure to follow the doctor's recommendations after hospital discharge [28-29]. Several different factors associated with low adherence to medication were identified, including female gender $[8,18,25,27,30]$, low level of education $[8,17]$, adverse effects of therapy [31], insufficient instructions given to patients [31], poor financial status preventing purchasing of medicines [31-33], lack of acceptance of the need for treatment by the patient [31], and poor relationship between the patient and medical staff [31-34].

Failure to follow the treatment plan is a relatively common problem, which is a serious and often underestimated factor limiting the effectiveness of treatment. Unfortunately, non-adherence to treatment often remains both common and difficult to detect [34]. Identifying the key determinants of low adherence and early discontinuation of treatment may aid in the development of interventions aimed at increasing adherence and addressing this high-risk population, in order to improve health outcomes [34-35].

\section{The adherence assessment}

There are some direct and indirect methods of assessing adherence to treatment; however, there is no single "gold standard" or a universal tool for determining the level of adherence [36-39]. Asking patients is the simplest and most frequently used method of adherence assessment. However, it has been shown that the data obtained in this way have limited credibility $[14,20]$. Objectification of patient-reported information is usually difficult and costly. On the other hand, some experts argue that the positive relationship between subjective data (e.g. questionnaires) and objective data (e.g. obtained from the medical reports) is high, so validated tools should be considered as a reliable instrument aimed at detecting non-adherence problems 
[40]. The application of specially developed questionnaires or scales to assess the risk of low adherence may be helpful in allowing extensive screening of patients. Moreover, well-designed questionnaires may also identify obstacles, gaps in patients' knowledge, and the problems in cooperation with patients. Nevertheless, even access to validated questionnaires does not diminish all potential obstacles associated with this social technique. For instance, due to memory-related issues, questionnaires can only measure non-adherence within a period of several weeks, which is not satisfactory from the scientific point of view and provides a limited scope of information for healthcare providers [40].

Recently, Buszko et al. [41] published an article validating the Adherence in Chronic Diseases Scale (ACDS). The ACDS allows assessment of adherence itself, as well as identification of the most important factors influencing adherence, such as: acceptance of a therapy plan, cooperation between a patient and health care professionals, and the economic status of a patient [42-44]. The ACDS scores range from 0 to 28 points. Results below 21 points, between 21-26 points, and above 26 points correspond respectively to low, medium, and high adherence, respectively. The internal consistency of the ACDS final version was assessed using Cronbach's alpha coefficient, and the value of 0.752 confirmed high reliability and homogeneity of the questionnaire [41]. The ACDS was subsequently applied in a single-centre, prospective, observational cohort clinical study with a six-month follow-up [45]. In a population of 221 patients with myocardial infarction treated with $\mathrm{PCl}$, lower scores for ACDS items 2 and 3 were associated with increased risk of acute coronary syndrome during follow-up (for item 2: $3.11 \pm 0.68$ vs. $3.45 \pm 0.73 ; p=0.02$, and for item 3: $3.28 \pm 0.89$ vs. $3.64 \pm 0.64 ; p=0.04)$, indicating the predictive value of these items [45]. The scale is simple to use and may be applied in everyday medical practice and for research purposes [44-45]. It can be successfully used as a tool to support medical staff in identifying patients requiring personalised educational activities [41].

\section{Summary}

Medication adherence is an issue of growing concern for those working to improve health system performance, and promoting adherence to medications offers a rare opportunity to simultaneously improve health outcomes while reducing costs. Jankowski at al. [46] pointed out different healthcare-related factors and patient-related factors affecting proper treatment of patients with cardiovascular diseases. According to Jankowska-Polanska at al. [47], the knowledge deficits contribute to a lack of adherence and worse clinical outcome. Therefore, education of patients regarding the risks and benefits of treatment is pivotal to avoid premature discontinuation of medication [48]. Nevertheless, no standard approach has been developed. Pharmaceutical care including educational interventions and reminding methods in patients with chronic diseases is also beneficial, both to the patients and to the entire healthcare system [49]. To sum up, we should admit that inter-professional collaboration is needed to improve adherence and outcomes. Thus, we should reveal the concept of 'concordance' as the deep agreement between patients and health-care providers, where the patients' needs are the matter of paramount importance [50].

\section{Conclusions}

The authors assumed that individual, complex health education started during hospitalisation and continued after discharge, explaining the pathophysiology and symptoms of the disease, elucidating goals and potential benefits of treatment, and highlighting the risk of premature termination of therapy, with use of additional methods helping patients to remember the treatment schedule will enhance adherence to treatment. There is an urgent need to develop and test a dedicated procedure covering all these activities.

\section{References}

1. Navarese EP, Verdoia M, Schaffer A, et al. Ischaemic and bleeding complications with new, compared to standard, ADP-antagonist regimens in acute coronary syndromes: a meta-analysis of randomized trials. QJM. 2011; 104(7): 561-569, doi: 10.1093/qjmed/hcr069, indexed in Pubmed: 21572108.

2. Tantry US, Jeong YH, Navarese EP, et al. Influence of genetic polymorphisms on platelet function, response to antiplatelet drugs and clinical outcomes in patients with coronary artery disease. Expert Rev Cardiovasc Ther. 2013; 11(4): 447-462, doi: 10.1586/erc.13.20, indexed in Pubmed: 23570358.

3. Kozinski M. Bielis L, Wisniewska-Szmyt J, et al. Diurnal variation in platelet inhibition by clopidogrel. Platelets. 2011; 22(8): 579-587, doi: 10.3109/09537104.2011.582900, indexed in Pubmed: 21627410.

4. Kubica A, Kozinski M, Grzesk G, et al. Genetic determinants of platelet response to clopidogrel. J Thromb Thrombolysis. 2011; 32(4): 459466, doi: 10.1007/s11239-011-0611-8, indexed in Pubmed: 21706290.

5. Kubica A, Koziński M, Grześk G, et al. [Clinical significance of interactions between clopidogrel and proton pump inhibitors]. Kardiol Pol. 2011; 69(6): 610-616, indexed in Pubmed: 21678305.

6. Latry P, Martin-Latry K, Lafitte M, et al. Dual antiplatelet therapy after myocardial infarction and percutaneous coronary intervention: analysis of patient adherence using a French health insurance reimbursement database. Eurolntervention. 2012; 7(12): 1413-1419, doi: 10.4244/EIJV7I12A221, indexed in Pubmed: 22522552.

7. Sabate' E. World Health Organization. Adherence to long-term therapies: evidence for action. http://www.who.int/chp/knowledge/publications/adherence full report.pdf.

8. Ho PM, Tsai TT, Maddox TM, et al. Delays in filling clopidogrel prescription after hospital discharge and adverse outcomes after drug-eluting stent implantation: implications for transitions of care. Circ Cardiovasc Qual Outcomes. 2010; 3(3): 261-266, doi: 10.1161/CIRCOUTCOMES.109.902031, indexed in Pubmed: 20407117. 
9. Ahmed R, Aslani P. What is patient adherence? A terminology overview. Int J Clin Pharm. 2014; 36(1): 4-7, doi: 10.1007/s11096-013-9856-y, indexed in Pubmed: 24104760.

10. Simpson SH, Eurich DT, Majumdar SR, et al. A meta-analysis of the association between adherence to drug therapy and mortality. BMJ. 2006; 333(7557): 15, doi: 10.1136/bmj.38875.675486.55, indexed in Pubmed: 16790458.

11. Kubica J, Adamski $P$, Buszko $K$, et al. Rationale and Design of the Effectiveness of LowEr maintenanCe dose of TicagRelor early After myocardial infarction (ELECTRA) pilot study. Eur Heart J Cardiovasc Pharmacother. 2017 [Epub ahead of print], doi: 10.1093/ehjcvp/pvx032, indexed in Pubmed: 29040445

12. Winter MP, Koziński M, Kubica J, et al. Personalized antiplatelet therapy with P2Y12 receptor inhibitors: benefits and pitfalls. Postepy Kardio Interwencyjnej. 2015; 11(4): 259-280, doi: 10.5114/pwki.2015.55596, indexed in Pubmed: 26677375

13. Stewart K, Mc Namara KP, George J. Challenges in measuring medication adherence: experiences from a controlled trial. Int J Clin Pharm. 2014; 36(1): 15-19, doi: 10.1007/s11096-013-9877-6, indexed in Pubmed: 24293282

14. Kubica A, Kasprzak M, Obońska K et al Discrepancies in assessment of adherence to antiplatelet treatment after myocardial infarction. Pharmacology. 2015; 95(1-2): 50-58, doi: 10.1159/000371392, indexed in Pubmed: 25592409.

15. Zhu B, Zhao Z, McCollam P, et al. Factors associated with clopidogre use, adherence, and persistence in patients with acute coronary syndromes undergoing percutaneous coronary intervention. Curr Med Res Opin. 2011; 27(3): 633-641, doi: 10.1185/03007995.2010.551657, indexed in Pubmed: 21241206.

16. Wijns W, Kolh P, Danchin N, et al. Task Force on Myocardial Revascularization of the European Society of Cardiology (ESC) and the European Association for Cardio-Thoracic Surgery (EACTS) European Association for Percutaneous Cardiovascular Interventions (EAPCI). Guidelines on myocardial revascularization. Eur Heart $J$. 2010; 31(20): 2501-2555, doi: 10.1093/eurheartj/ehq277, indexed in Pubmed: 20802248.

17. Canpolat $U$, Yorgun $H$, Atalar $E$ Simultaneous subacute thrombosis of bare metal coronary stents in two different arteries early after clopidogrel cessation. Cardiol J. 2012; 19(3): 309-313, doi: 10.5603/cj.2012.0054, indexed in Pubmed: 22641551.

18. Jeremias A, Sylvia B, Bridges J, et al. Stent thrombosis after successful sirolimus-eluting stent implantation. Circulation. 2004; 109(16) 1930-1932, doi: 10.1161/01.CIR.0000127105.99982.21, indexed in Pubmed: 15078797.

19. lakovou I, Schmidt T, Bonizzoni E, et al. Incidence, predictors and outcome of thrombosis after successful implantation of drug-eluting stents. JAMA. 2005; 293(17): 2126-2130, doi 10.1001/jama.293.17.2126, indexed in Pubmed: 15870416

20. Kubica A, Kochman W, Bogdan M, et al. The influence of undergone percutaneous coronary interventions, and earlier hospitalizations with myocardial infarction on the level of knowledge and the effectiveness of health education in patients with myocardial infarction. Adv Interv Cardiol. 2009; 5: 25-30.

21. Lam WY, Fresco P. Medication Adherence Measures: An Overview. Biomed Res Int. 2015; 2015: 217047, doi: 10.1155/2015/217047, indexed in Pubmed: 26539470.

22. Yusuf S, Islam S, Chow CK, et al. Prospective Urban Rural Epidemiology (PURE) Study Investigators. Use of secondary prevention drugs for cardiovascular disease in the community in high-income, middle-income, and low-income countries (the PURE Study): a prospective epidemiological survey. Lancet. 2011; 378(9798): 1231-1243, doi: 10.1016/S0140-6736(11)61215-4, indexed in Pubmed: 21872920.

23. Spertus JA, Kettelkamp R, Vance C, et al. Prevalence, predictors, and outcomes of premature discontinuation of thienopyridine therapy after drug-eluting stent placement: results from the PREMIER registry Circulation. 2006; 113(24): 2803-2809, doi: 10.1161/CIRCULATIONAHA.106.618066, indexed in Pubmed: 16769908.

24. Kubica A, Obońska K, Fabiszak T, et al. Adherence to antiplatele treatment with P2Y12 receptor inhibitors. Is there anything we can do to improve it? A systematic review of randomized trials. Curr Med Res Opin. 2016; 32(8): 1441-1451, doi: 10.1080/03007995.2016.1182901 indexed in Pubmed: 27112628.

25. Kubica A Kasprzak M, Siller-Matula J, et al. Time-related changes in determinants of antiplatelet effect of clopidogrel in patients after myocardial infarction. Eur J Pharmacol. 2014; 742: 47-54, doi: 10.1016/j ejphar.2014.08.009, indexed in Pubmed: 25199965.

26. Holt EW, Rung AL, Leon KA, et al. Medication Adherence in Older Adults: A Qualitative Study. Educ Gerontol. 2014; 40(3): 198-211 doi: 10.1080/03601277.2013.802186, indexed in Pubmed: 25214707.
27. Ferreira-González I, Marsal JR, Ribera A, et al. Double antiplatelet therapy after drug-eluting stent implantation: risk associated with discontinuation within the first year. J Am Coll Cardiol. 2012; 60(15): 1333-1339, doi: 10.1016/j.jacc.2012.04.057, indexed in Pubmed: 22999716

28. Sengstock D, Vaitkevicius P, Salama A, et al. Under-prescribing and non-adherence to medications after coronary bypass surgery in Ider adults: strategies to improve adherence. Drugs Aging. 2012; 29(2): 93-103, doi: 10.2165/11598500-000000000-00000, indexed in Pubmed: 22239673

29. Collins SD, Torguson R, Gaglia MA, et al. Does black ethnicity influence the development of stent thrombosis in the drug-eluting stent era? Circulation. 2010; 122(11): 1085-1090, doi: 10.1161/CIRCULATIONAHA.109.907998, indexed in Pubmed: 20805432.

30. Shimony A, Zahger D, llia R, et al. Impact of the community's socioeconomic status on characteristics and outcomes of patients undergoing percutaneous coronary intervention. Int J Cardiol. 2010; 144(3): 379382, doi: 10.1016/j.ijcard.2009.04.033, indexed in Pubmed: 19446896.

31. Ferreira-González I, Marsal JR, Ribera A, et al. Background, incidence, and predictors of antiplatelet therapy discontinuation during the first year after drug-eluting stent implantation. Circulation. 2010; 122(10): 1017-1025, doi: 10.1161/CIRCULATIONAHA.110.938290, indexed in Pubmed: 20733100

32. Tuppin P, Neumann A, Danchin N, et al. Evidence-based pharmacotherapy after myocardial infarction in France: adherence-associated factors and relationship with 30-month mortality and rehospitalization. Arch Cardiovasc Dis. 2010; 103(6-7): 363-375, doi: 10.1016/j. acvd.2010.05.003, indexed in Pubmed: 20800800

33. Osterberg L, Blaschke T. Adherence to medication. $N$ Engl J Med. 2005; 353(5): 487-497, doi: 10.1056/NEJMra050100, indexed in Pubmed: 16079372

34. Muntner P, Mann DM, Woodward M, et al. Predictors of low clopidogrel adherence following percutaneous coronary intervention. Am J Cardiol. 2011; 108(6): 822-827, doi: 10.1016/j.amjcard.2011.04.034, indexed in Pubmed: 21741610

35. Roth GA, Morden NE, Zhou W, et al. Clopidogrel use and early outcomes among older patients receiving a drug-eluting coronary artery stent. Circ Cardiovasc Qual Outcomes. 2012; 5(1): 103-112, doi: 10.1161/CIRCOUTCOMES.111.962704, indexed in Pubmed: 22147885

36. Vrijens B, De Geest S, Hughes DA, et al. ABC Project Team. A new taxonomy for describing and defining adherence to medications. Br J Clin Pharmacol. 2012; 73(5): 691-705, doi: 10.1111/j.13652125.2012.04167x $x$, indexed in Pubmed: 22486599.

37. DiMatteo MR. Variations in patients' adherence to medical recommendations: a quantitative review of 50 years of research. Med Care. 2004; 42(3): 200-209, doi: 10.1097/01.mlr.0000114908.90348.f9, indexed in Pubmed: 15076819

38. Singh N, Squier C, Sivek C, et al. Determinants of compliance with antiretroviral therapy in patients with human immunodeficiency virus: prospective assessment with implications for enhancing compliance. AIDS Care. 1996; 8(3): 261-269, doi: 10.1080/09540129650125696, indexed in Pubmed: 8827119.

39. Bender BG, Rand C. Medication non-adherence and asthma treatment cost. Curr Opin Allergy Clin Immunol. 2004; 4(3): 191-195, doi: 10.1097/00130832-200406000-00009, indexed in Pubmed: 15126940.

40. Lehmann A, Aslani $P$, Ahmed $R$, et al. Assessing medication adherence: options to consider. Int J Clin Pharm. 2014; 36(1): 55-69, doi: 10.1007/s11096-013-9865-x, indexed in Pubmed: 24166659.

41. Buszko K Obońska K, Michalski P et al. The Adherence Scale in Chronic Diseases (ASCD). The power of knowledge: the key to successful patient - health care provider cooperation. Med Res J. 2016; 1(1): 37-42, doi: 10.5603/mri.2016.0006.

42. Kane S, Shaya F. Medication non-adherence is associated with increased medical health care costs. Dig Dis Sci. 2008; 53(4): 1020-1024, doi: 10.1007/s10620-007-9968-0, indexed in Pubmed: 17934828.

43. Haynes RB, Yao X, Degani A, et al. Interventions for enhancing medication adherence. Cochrane Database Syst Rev. 2005; 4: 26-33, doi: 10.1002/14651858.cd000011.pub2.

44. Kosobucka A, Michalski P, Pietrzykowski $Ł$, et al. Adherence to treatment assessed with the Adherence in Chronic Diseases Scale in patients after myocardial infarction. Patient Prefer Adher. 2018; Volume 12: 333-340, doi: 10.2147/ppa.s150435.

45. Kubica A, Kosobucka A, Michalski P, et al. The Adherence in Chronic Diseases Scale - a new tool to monitor implementation of a treatment plan. Folia Cardiol. 2017; 12: 19-26, doi: 10.5603/FC.2016.0000.

46. Jankowski P, Czarnecka D, Łukaszewska A, et al. Factors related to the effectiveness of hypercholesterolemia treatment following hospitalization for coronary artery disease. Pol Arch Med Wewn. 
2016; 126(6): 388-394, doi: 10.20452/pamw.3447, indexed in Pubmed: 27362391

47. Jankowska-Polańska B, Uchmanowicz I, Dudek K, et al. Relationship between patients' knowledge and medication adherence among patients with hypertension. Patient Prefer Adherence. 2016 10: 2437-2447, doi: 10.2147/ppa.s117269, indexed in Pubmed: 27994443.

48. Kubica A, Obońska K, Kasprzak M, et al. Prediction of high risk of non-adherence to antiplatelet treatment. Kardiol Pol. 2016;
74(1): 61-67, doi: 10.5603/KP.a2015.0117, indexed in Pubmed: 26101025.

49. Swieczkowski D, Mogielnicki M, Merks P, et al. Pharmaceutical services as a tool to improve outcomes in patients with cardiovascular diseases. Int J Cardiol. 2016; 222: 238-241, doi: 10.1016/j. ijcard.2016.07.189, indexed in Pubmed: 27497101.

50. Aslani P, Schneider MP. Adherence: the journey of medication taking, are we there yet? Int J Clin Pharm. 2014; 36(1): 1-3, doi: 10.1007/s11096-013-9901-x, indexed in Pubmed: 24310103. 